\title{
PETRUS HISPANUS EN URBINO Y EL BASTÓN DEL GONFALONIERE: EL PROBLEMA PEDRO BERRUGUETE EN ITALIA Y LA HISTORIOGRAFÍA ESPAÑOLA ${ }^{1}$
}

\author{
POR \\ FERNANDO MARÍAS y FELIPE PEREDA \\ Universidad Autónoma de Madrid
}

\begin{abstract}
La piedra angular de la biografia del pintor palentino Pedro Berruguete es un documento citado por el erudito Luigi Pungileoni (1822) en el que un cierto «Petrus Hispanus», pintor, se encontraba en Urbino. Nunca transcrito ni reencontrado, esta noticia soporta la mayor parte del peso de la supuesta formación italiana de una de las cabezas de la pintura española del Renacimiento. El hallazgo de dicho documento, la transcripción de su contenido y la incorporación de nuevos documentos igualmente inéditos, permiten no solo determinar rasgos significativos del hasta hoy ignoto «Petrus Hispanus», sino reconsiderar la tradición historiográfica que ha mantenido sin reservas la identificación entre los dos artistas.

Palabras clave: Petrus Hispanus. Pedro Berruguete. Justo de Gante. Joos van Wassenhove. Pintura del Renacimiento en España. Hispanoflamenco. Palacio Ducal de Urbino.
\end{abstract}

The cornerstone of the biography of the Palencian painter Pedro Berruguete is a document cited by the erudite Luigi Pungileoni (1822) in which a certain «Petrus Hispanus», painter, was in Urbino. Never transcribed or found again, this notice bears the greater part of the weight of the supposed Italian formation of one of the leading figures of Spanish Renaissance painting. Now, the discovery of this document, the transcription of its contents and the incorporation of new documents likewise previously unpublished, allow for the discernment of significant features of the until today unknown «Petrus Hispanus», as well as the reconsideration of the historiographic tradition which has maintained without question the crossed identification between these two artists.

Key words: Petrus Hispanus. Pedro Berruguete. Justo de Gante. Joos van Wassenhove. Renaissance painting in Spain. Hispano-Flemish. Ducal Palace of Urbino.

Aunque todavía esté por escribirse la historia de la historia de la pintura española, existen episodios, que incluso podrían ser tachados de lugares comunes, cuyo carácter ha resultado decididamente fundacional. El papel de Pedro Berruguete como el pintor español, que no italiano, que introdujera el Renacimiento en España es indiscutiblemente uno de ellos; como señalara Diego Angulo en 1954, en el volumen del Ars Hispaniae dedicado a la Pintura del Renacimiento, el palentino debía ser considerado «el patriarca del cuatrocentismo en Castilla» ${ }^{2}$.

\footnotetext{
' Este trabajo es reelaboración y ampliación de la ponencia «Petrus Hispanus pittore a Urbino» presentada al Convegno Internazionale di Studi 'Francesco di Giorgio alla Corte di Federico da Montefeltro', Comune di Urbino, Urbino (Italia), 2001. Adelanta algunos aspectos de una investigación monográfica en curso de realización.

${ }^{2}$ D. Angulo Íñiguez, Pintura del Renacimiento, Ars Hispaniae XII, Plus Ultra, Madrid, 1954, p. 84.
} 
Esta tradición se ha mantenido hasta nuestros días ${ }^{3}$, empleando una concepción del término renacentista tan lábil y ampliando indiscriminadamente hasta tal extremo su campo semántico, que ha quedado desprovisto de todo carácter funcional.

La madeja historiográfica del «problema Berruguete-Renacimiento», a pesar de su carácter de tópico que no se discute, requiere ser desenredada en esta doble vertiente, para solo entonces poder individuar los rasgos de una discusión que se ha obviado de forma sistemática.

En 1927 Juan Allende-Salazar publicaba su artículo «Pedro Berruguete en Italia» ${ }^{4}$, el primer trabajo en lengua castellana que identificó a Pedro Berruguete con el anónimo artista español que — según Pablo de Céspedes_ había pintado en un «camarino» del Duque de Urbino, y con el Pietro Spagnuolo pittore que el erudito del siglo xIx Luigi Pungileoni había encontrado en un documento de 1477. Este autor juntó estos tres retales para perfilar una figura pictórica, con la que «reivindicar para el arte español el admirable conjunto pictórico que adornaba el palacio de Urbino», y cuyo arte inauguraba nuestra escuela nacional en los tópicos términos del «incomparablemente robusto y hermoso realismo del arte español»; para Allende-Salazar, Berruguete «... anuncia[ba] los deliciosos príncipes de Velázquez y las figuras infantiles de Murillo y de Goya...» Sin entrar a deconstruir los compromisos ideológicos de corte nacionalista de este trabajo, por otro lado tan ingenuamente declarados por su autor ${ }^{5}$, Allende-Salazar iba más allá de la construcción de una peculiar biografía para dibujar mecánicamente una ecuación de dos términos - Pedro Berruguete en Italia, Berruguete renacentista - y una sola conclusión: la incorporación de España como protagonista al Renacimiento europeo.

Si algunas dudas se habían erigido frente a tal identificación del Pietro Spagnuolo pittore y Berruguete por parte de los historiadores del ducado montefeltriano ${ }^{6}$, dudas ante las que la historiografía española hizo oídos sordos, otras - entre ellas la de uno de los que suscribe estas páginas ${ }^{7}$ - se levantaron ante la concepción del arte renacentista que esta construcción conllevaba. Este escepticismo surgía ante la aceptación acrítica desde comienzos del siglo XIX (sin «falsar» o verificar) de los datos recibidos, fuera su estancia en Urbino en 1477 o su presencia en Toledo en 1483, al año de haber fallecido el duque; y también ante la simplificadora

\footnotetext{
${ }^{3}$ Por ejemplo en la reciente monografía de P. Silva Maroto, Pedro Berruguete, Junta de Castilla-León, Salamanca, 1998, y sus sucesivas puestas al día en «Pintura y sociedad en Castilla en época de los Reyes Católicos», en Imágenes y promotores en el arte medieval. Miscelánea homenaje a Joaquín Yarza Luaces, Universidad Autónoma de Barcelona, Barcelona 2001, pp. 619-631; «La pintura castellana en tiempos de Gil de Siloe», en Actas del Congreso Internacional sobre Gil Siloe y la escultura de su época, Institución Fernán González, Burgos, 2001, pp. 91-112; y «Flanders and the Kingdom of Castile», en The Age of Van Eyck, 1430-1530. The Mediterranean World and early Netherlandish Painting, ed. Till-Holger Borchert, Ludion, Brujas, 2002, pp. 143-155.

${ }^{4}$ J. Allende Salazar, «Pedro Berruguete en Italia», Archivo Español de Arte y Arqueología, 8, 1927, pp. 133-138. Como reconocía el autor, el Conde Carlo Gamba había adelantado en 1925, en el semanario «Il Marzocco», algunas de las ideas que ambos compartían, apoyadas en la autoridad oral del historiador del arte Roberto Longhi; mientras Longhi solo llegó a publicar sus conclusiones sobre las «Alegorías», que atribuyó a un Berruguete que habría frecuentado el taller de Piero della Francesca (P. Longhi, Piero della Francesca, Roma, 1927, pp. 76, 123 y 180), Gamba las dió a conocer en su «Pietro Berruguete», Dedalo, marzo 1927.

${ }^{5}$ En frases sin desperdicio como la siguiente ( $\mathrm{Ibid}$, p. 137): «los que sin patrioterías inoportunas vamos afirmando la enorme influencia mundial de los españoles en la literatura y en las artes, debemos congratularnos de todo corazón de que tras el reconocimiento pleno de la hegemonía de nuestra pintura en los dominios de Aragón en Italia y sus islas, el trabajo de Gamba y el que prepara Longhi vayan dando a Pedro Berruguete la consideración extraordinaria merecida por tal artista...»

${ }^{6}$ C. H. Clough, «Pedro Berruguete and the Court of Urbino: a Case of wishful Thinking», en Notizie da Palazzo Albani, III, 1, 1994, pp. 17-24 y en The Duchy of Urbino in the Renaissance, Variorum Reprints, Londres, 1981, pp. X, 1-13.

${ }^{7}$ F. Marías, El largo siglo XVI. Los usos artísticos del Renacimiento español, Taurus, Madrid, 1989, pp. 171-181. Por su parte, Joaquim Garriga, «Dipingere lontano da Piero. La resa spaziale di Pedro Berruguete e i modi 'prospectici' artigianali», en Piero della Francesca tra arte e scienza. Atti del Convegno Internazionale di Studi, Venecia, 1996, pp. 475-512, insistió en la endeblez de los argumentos para hacer de Berruguete un pintor dominador de la perspectiva monofocal italiana a la manera de Piero o Paolo. Ambos, al poner en entredicho la estancia de Berruguete en Urbino, intentábamos cuestionar los encadenamientos mecánicos de hechos, ideas y etiquetas estilísticas antes señalados, ante una historiografía tan «datolátrica» como la nuestra.
}

AEA, LXXV, 2002, 300, pp. 361 a 380 
tesis de la renuncia, por parte del Berruguete de vuelta en Castilla, de los nuevos principios artísticos que habría adquirido en el ambiente urbinés de los Piero della Francesca, Paolo Uccello, Francesco di Giorgio Martini, Baccio Pontelli, Giuliano da Maiano, etc.

Este artículo, en consecuencia, es fruto de una búsqueda documental, cuyos resultados lejos de agotarse en sí mismos, abren nuevos interrogantes y también unas vias desde las que poder replantearse unos problemas hasta la fecha totalmente enquistados.

Petrus Hispanus y Perus Spagnuolus: dos nombres para un pintor español en Urbino

Desde el momento en que Vespasiano da Bisticci silenció ${ }^{8}$, en sus Vite di uomini illustri (1482-1498), el nombre del «maestro solenne» que Federico da Montefeltro había llevado a Urbino por sus conocimientos de la pintura al óleo («per non trovare maestri a suo modo in Italia, che sapessino colorire in tavole ad olio, mandò infino in Fiandra per trovare uno maestre solenne, e fello venire a Urbino, dove fece fare molte pitture di sua mano solennisseme») ${ }^{9}$, se abrió una incógnita que no han logrado cerrar ni las aportaciones documentales ni la crítica filológica de la pintura europea ${ }^{10}$.

Por el contrario, una y otra metodología insisten en hacer de este anónimo maestro dos o incluso tres personalidades tan distintas como para atribuirles orígenes geográficos tan alejados como Flandes, España e Italia, y que se disputarían — como es bien sabido- un conjunto de obras tan plural como «La Comunión de los apóstoles» de la cofradía del Corpus Domini (Fig. 1), los uomini illustri del studiolo ducal de Urbino y una serie de tablas que podrían proceder tanto de esta fábrica como del palacio ducal de Gubbio, y que nos presentarían al duque en diferentes situaciones junto a una serie de alegorías de las Artes Liberales.

Frente a tal tradición, disponemos de tres diferentes fuentes de información cuyo examen atento podría arrojar más luz a una escena que ha permanecido en la penumbra hasta la fecha, aunque estas tres fuentes resultan al mismo tiempo mutuamente contradictorias.

La primera de ellas está constituida por dos tradiciones en origen orales, pero que nos han llegado naturalmente por escrito, que se mantuvieron vivas en Italia entre los siglos XVI y XVIII.

\footnotetext{
${ }^{8}$ Ni Justo ni Pedro son citados sorprendentemente por el padre de Rafael de Urbino, Giovanni Santi (ca. 1440-1494) tanto en su «Cronaca rimata» (ca. 1482), como en su «La vita e le gesta di Federico di Montefeltro duca d'Urbino» (ca. 1482), ed. Luigi Michelini Tocci, Città del Vaticano, 1985, caps. Ivi-lvii y xci. Véase también Grazia Calegari, Giovanni Santi. El paternal mio nido, Comune, Colbordolo, 1994.

${ }^{9}$ V. da Bisticci, Virorum illustrium CIII qui saeculo XV extiterunt, ed. A. Bartoli, Florencia, 1859. Véase Á. Gómez Moreno, «Los intelectuales europeos y españoles a ojos de un librero florentino: las Vite de Vespasiano de Bisticci (14211498)», Studi Ispanici, 1999, pp. 33-47.

${ }^{10}$ La identificación tradicional de Giusto di Gand con Joos van Wassenhove ha sido sostenida desde 1900 por G. Hulin de Loo, «Une note relative au peintre Juste de Gand», Bulletin de la Société d'Histoire et d'Archéologie de Gand, 1900, pp. 64-68; V. van der Haegen, "Avons-nous trouvé le véritable nom de Juste de Gand?», Petite Revue illustré de l'art et de l'archéologie en Fladre, Gante, agosto 1901, p. 109; e A. de Ceuleneer y M. H. Bernath, Juste de Gand (Joos van Wassenhove), Bruselas, 1911, hasta nuestros días (M. L. Evans, «'Un maestro solenne' Joos van Wassenhove in Italy», Nederlands Kunsthistorisch Jaarboek, 44, 1993, pp. 75-110; L. Campbell, «Justus of Ghent», en National Gallery Catalogues: The Fifteenth Century Netherdandish Schools, National Gallery, Londres, 1998, pp. 267-292). Este había sido el artista que entraba en 1460 en el gremio de Amberes y en 1464 en el de Gante, donde estaba en contacto con Hugo van der Goes y Sander Beninc, partiendo para Roma en algún momento situado antes de febrero de 1474; habría dejado como obra príncipal el Tríptico de la Crucifixión (antes de 1470) de la colegiata de Saint-Jean de Gante (hoy catedral de San Bavón); solo habría realizado, como obra documentada, cuatro escudos de armas pontificias para la colegiata de Saint-Jean en 1468.

Sólo P. Eeckhout, «De Justus de Gand à Hugo Van der Goes ou le mythe de Joos Van Wassenhove», Bulletin des Musées Royaux des Beaux-Arts de Belgique, 1-4, 1992-1993, pp. 9-33, y «Juste de Gand», en Les Primitifs flamands et leur temps, ed. Brigitte de Patoul y Roger van Schoute, Lovaina la Nueva, 1994, pp. 404-413 y 639-640, propone como improbable alternativa un Justo di Gualteri di Guante, «ricamatore» activo en Florencia de 1445 a 1448 y miembro de la compagnia di Santa Barbara de la iglesia de los Servitas de la Annunziata de Firenze, personaje documentado por da M. Battistini, La Confrérie de Saint-Barbe des Flamands à Florence, Bruselas, 1931, doc. 1, p. 65 e doc. 11, p. 102.
}

AEA, LXXV, 2002, 300, pp. 361 a 380 
La segunda fuente sería la estrictamente documental, iniciada a comienzos del siglo xix con la publicación del regesto de datos de Luigi Pungileoni (Correggio, 1762-Roma, 1844), utilizando fondos archivísticos exhumados por el profesor de Urbino Antonio Corradini, limitándose en lo básico a una única obra de las citadas, en concreto la pala de la Confraternita del Corpus Domini ${ }^{11}$. La tercera de estas fuentes se basa en el estudio moderno de la técnica y del estilo del citado conjunto pictórico.

Comenzando nuestro análisis por la primera de esas fuentes de información, la de los relatos orales «escriturizados», resulta fácil distinguir dos tradiciones, que divergen tanto respecto al objeto artístico de su atención como respecto al artista al que se vinculan. La más antigua de ellas es retrotraíble a la estancia en Urbino de 1548 de Giorgio Vasari y a las dos ediciones de 1550 y 1568 de sus Vite ${ }^{12}$. Al historiar la técnica del óleo, Vasari señaló como uno de sus primeros prácticantes en Italia a «Giusto da Guanto, che fece la tavola della Comunione de ' 1 Duca d'Urbino e altre pitture». A partir de 1550 esta información atributiva reaparece, de forma inmediata y con mínimas variaciones, en las páginas de la Descrittione di tutti i Paesi Bassi, altrimenti detti Germaniae inferiore de 1567 de Lodovico Guicciardini ${ }^{13}$, y en las del elogio de Gante de Antoine Sanders (1586-1664) de $1624^{14}$. En este sentido no son contradictorias las siguientes noticias sobre Justo de Gante en Italia proporcionadas por el erudito urbinés Bernardino Baldi (1553-1617), de $1604^{15}$, y del anónimo autor de la descripción de 1655 de la iglesia del Corpus Domini; ambos hicieron de Justo un «todesco pittore habitante in Urbino al tempo del Duca Federico Montefeltrio, la cui effigie in esse è dipinta, et anche del istesso pittore, e d'altri» ${ }^{16}$.

La segunda tradición es absolutamente minoritaria, aunque pueda llevarse hasta la década de los años setenta del Cinquecento, estando representada por el pintor y tratadista cordobés Pablo de Céspedes (ca. 1538-1608), estante en Italia entre 1567 y 1576 y de nuevo en 1582 84. A pesar de que ignoramos si Céspedes visitó Urbino, el canónigo español señaló en sus notas manuscritas sobre la pintura moderna española de 1604, y tras citar a los pintores que florecieron a fines del Quattrocento como Pedro Berruguete y Alejo Fernández, la presencia activa «de otro pintor español, que en el palacio de Urbino, en un camarino del duque, pintó unas cabezas a manera de retratos de hombres famosos, buenas a maravilla» ${ }^{17}$. En contra de lo que normalmente se afirma contra lógica interna, Céspedes no acertó a identificar al «español» de Urbino con Pedro Berruguete, bien porque no llegara a ver jamás la obra de éste en la ciudad ducal y le fuera imposible establecer cualquier tipo de vínculo estilístico entre ellos, bien porque, tras conocer las pinturas del studiolo, estimara que se encontraba ante dos personalidades distintas.

La identificación de un pintor español ha resultado extraña hasta nuestros días e incluso ha sido cuestionada, a pesar de que en el siglo XVIII Ubaldo Tossi, en $1744^{18}$, y Michelarcangelo

\footnotetext{
${ }^{1}$ L. Pungileoni, Elogio storico di Giovanni Santi pittore e poeta padre del gran Raffaello di Urbino, Urbino, Vincenzo Guerrini, 1822, ed. Ranieri Varese, Torre d'Orfeo, Roma, 19942, p. 49.

${ }^{12} \mathrm{G}$. Vasari (1550), Le vite de' più eccelenti architetti, pittori et scultori italiani, da Cimabue insino a' tempi nostri, 1550, Einaudi, Turín, 1991, I, p. 68; (1568), ed. Vasari-Milanesi (1906), Le Opere di Giorgio Vasari, ed. Paola Barocchi, Sansoni, Florencia, 1973, I, p. 185.

${ }_{13}$ Amberes, 1567, p. 98.

${ }^{14}$ A. Sanderus, De Gandavensis eruditionis fama claris libri tres, Amberes, 1624, p. 79.

${ }^{15}$ B. Baldi, Della vita e de' fatti di Federigo di Montefeltro, duca di Urbino, ed. F. Zuccardi, Roma, III, pp. $241-242$.

${ }^{16}$ Citado por J. Lavalleye, Le Palais ducal d'Urbin, Les Primitifs Flamands, I. Corpus de la peinture des anciens PaysBas méridionaux au Quinzième siècle, Bruselas, 1964, p. 39.

${ }^{17}$ P. de Céspedes, Discurso de la comparación de la antigua y moderna pintura (1604), en Anales de la Real Academia de San Fernando, III, 1, 1939, pp. 49-50.

${ }^{18}$ U. Tossi, «Catalogo delle pitture che si conservano nella città metropoli d'Urbino», en Miscellanea storica, Urbino, 1744, Biblioteca Universitaria di Urbino, Comune, Ms. 93, fol. $224 \mathrm{v}^{\circ}$, citado por J. Lavalleye, 1964, p. 40.
}

$A E A, \mathrm{LXXV}, 2002,300$, pp. 361 a 380 

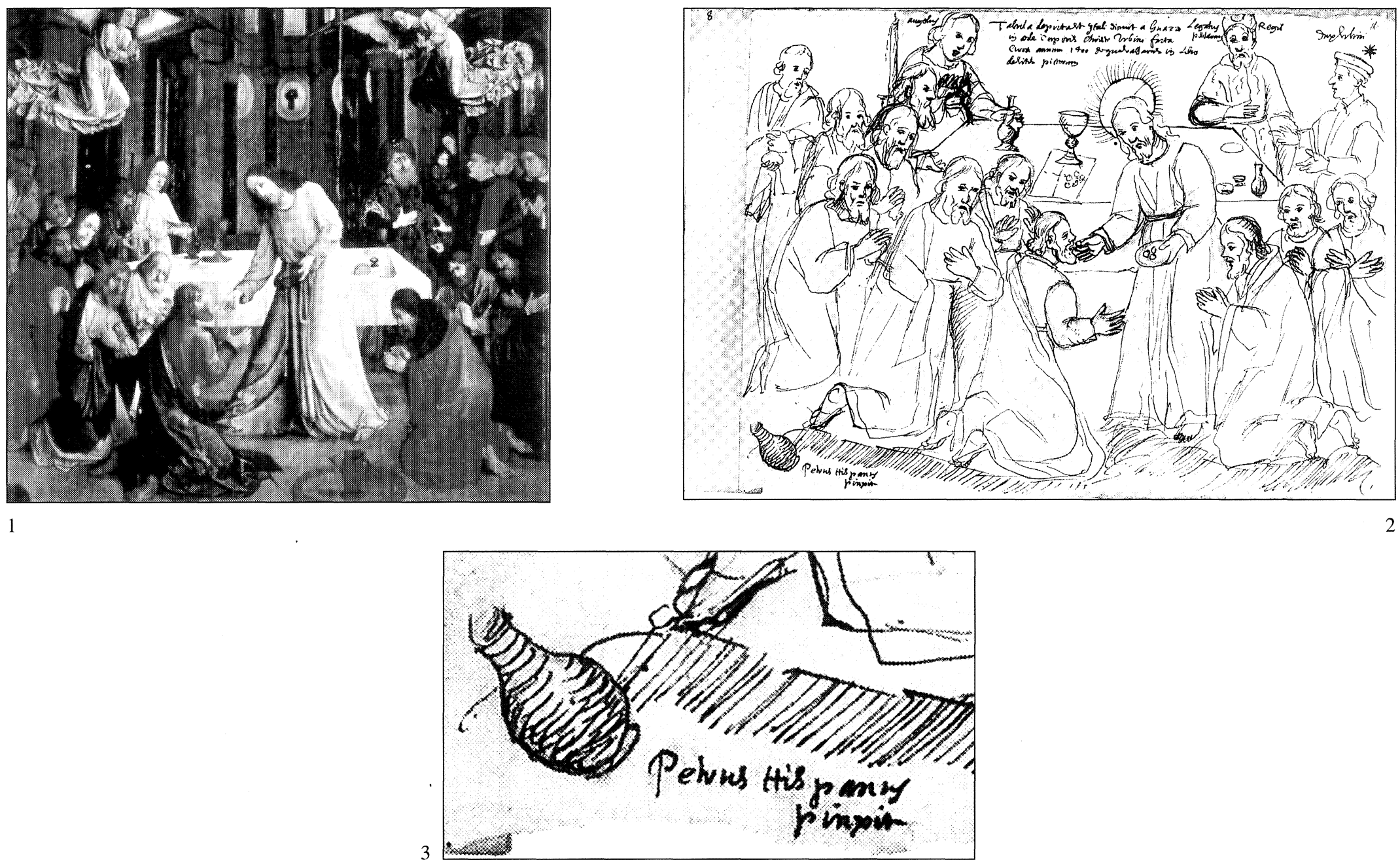

Fig. 1. [Petrus Hispanus] = Justo de Gante, La Comunión de los Apóstoles, Urbino, Galleria Nazionale delle Marche

Collection Dupuy, vol. 630 , fo 12 vionale

Fig. 3. [UrbinoNaudé-detalle] = Gabriel Naudé, Detalle de La Comunión de los Apóstoles de Justo de Gante (1632), París, Bibliothèque Nationale, Collection Dupuy, vol. 630 , fo 12 v. I I. 
Dolci (1724-1803), en $1775^{19}$, en sus respectivos catálogos de la pintura de las iglesias y palacios de la ciudad de Urbino, insistieran en que la nacionalidad de Justo de Gante había sido la española.

Hoy, sin embargo, gracias al descubrimiento de Vladimír Juřen ${ }^{20}$, sabemos de la existencia de un latinizado «Petrus Hispanus», cuya firma resultaba todavía legible en 1632, en la parte inferior del lienzo de la «Comunión de los apóstoles», y donde era presentado además como su propio autor por medio de un elocuente «pinxit» (Fig. 2-3). La fuente de esta información es un dibujo que el libertino erudito Gabriel Naudé (1600-1653), importante bibliófilo y bibliotecario francés, realizó in situ en 1632 para dar a conocer a su amigo Jacques du Puy los hallazgos artísticos que había realizado en Urbino ${ }^{21}$. En este dibujo, Naudé añadió diferentes observaciones, desde la citada cartela hasta la identificación de algunos de los personajes retratados en la parte derecha del cuadro, así como que podía encontrarse ulterior información sobre esta obra en las Vite de Vasari, donde, sin embargo, se habría encontrado recogida otra autoría.

Esta nueva información es solo aparentemente desconcertante al contradecir la tradición historiográfica que surge con Vasari, y atribuir a «Petrus» la tabla de la confraternita, puesto que en el siglo xviII, como hemos visto, se ha había intentado conciliar la información de una cartela - cuando menos todavía parcialmente visible - con la autoridad de Vasari, creando un imposible «Giusto da Guanto spagnolo».

Los documentos de la cofradía del Corpus Domini, en su Libro B,1 (1465-1513) ${ }^{22}$, algunos de los cuales fueron adelantados por Luigi Pungileoni en 1822 a partir de transcripciones decimonónicas del abogado Alipio Alippi y, tras creerse perdido el volumen, pudieron ser consultados de nuevo en el original por Jacques Lavalleye en 1959, siendo la fuente archivística fundamental para la reconstrucción del proceso. En marzo de 1465 la institución piadosa de Urbino había decidido emprender la ejecución de la pala de su iglesia, que se prolongaría al menos durante diez años.

Tras un intento de contratación de un pintor de Foligno en 1466-67, en 1467 inició Paolo Uccello - miembro de la cofradía desde ese mismo año ${ }^{23}$ - la realización de la pintura de la predela, cuyo pago se prolongó hasta octubre de 1469; pocos meses antes, en abril, Piero della Francesca había visitado Urbino para estudiar la posibilidad de hacerse cargo de la pintura de la gran tabla principal. En esta fecha el soporte de madera («la tavola») estaba listo, aunque su marco arquitectónico («il quadro della tavola»), iniciado el mismo 1467, no se terminaría hasta 1471. Desconocemos las razones por las cuales Piero no aceptó el encargo, quizá porque hubiera debido simultanearlo con la pala de San Bernardino (ca. 1472-74).

En cualquier caso, en febrero de 1473 aparecía en escena Giusto da Guanto «depintore», quien contrataría su realización poco antes del 12 de febrero de 1473 , fecha de un primer pago ${ }^{24}$. La cronología y los motivos de la aparición de Justo de Gante constituyen en sí mis-

\footnotetext{
${ }^{19}$ M. Dolci, «Notizie delle pitture che si trovano nelle chiese e nei palazzi d'Urbino» (1775), ed. L. Serra, en Rassegna Marchigiana, 11, 1933, p. 300, también citado por J. Lavalleye, 1964, p. 40.

${ }^{20}$ V. JuÍen, «Pietro Spagnolo et Juste de Gand. Un dessin d'après le tableau d'autel du Corpus Domini à Urbin», Revue de l'Art, 117, 3, 1997, pp. 48-53. El dibujo, de la Colección Du Puy (vol. 630, fol. 12 vo ) de la Bibliothèque Nationale de France, lleva las inscripciones siguientes: «Tabula depicta ut Itali dicunt a guazzo, in aede Corporis Christi Urbini facta, circa annum 1400 de qua Vasarus in libro, de Vitis pictorum»; «Legatus Regis persarum»; «Dux Urbini»; «Petrus Hispanus pinxit».

${ }^{21}$ Véase ahora, sobre este «libertino erudito», Carlo Ginzburg, Ojazos de madera. Nuevas reflexiones sobre la distancia, Península, Barcelona, 2000, pp. 66-71.

${ }^{22}$ Una excelente transcripción de los más importantes documentos en L. Moranti, La Confraternita del Corpus Domini de Urbino, Il Lavoro, Ancona-Bolonia, 1990.

${ }^{23}$ Urbino, Archivio della Confraternita del Corpus Domini, Libro B, 1, fol. 38.

${ }^{24}$ Recibió 421/2 bolognini. Otros pagos en el 9 de septiembre de 1473 (64 bolognini), 7 de marzo de 1474 (6 florines y 4 florines), 9 de septiembre de 1474 (64 bolognini) y finalmente el 25 de octubre de 1474 .
}

AEA, LXXV, 2002, 300, pp. 361 a 380 
mos ya un problema nunca advertido. El viaje desde Gante a Italia, se basa en un documento de $1475^{25}$, por el que se indicaba que Justo se había marchado a Roma. Dicho documento procede de las cuentas realizadas el 14/15 de febrero de 1475, tras la muerte del Señor de Nazareth Niklaas van der Zickele, a petición de su hijo Philippe. Entre los pagos abonados por el pintor Hugo van der Goes por su casa de la Abadía de San Pedro (Sint-Pietersabdij), en el Hoogpoort de Gante, cerca de la confluencia del Escalda y el Lys, y propiedad de la familia van der Zickele, se le deducían diferentes cantidades que había ya abonado para reparaciones, rentas y como adelanto de dinero que la viuda de Niklaas y madre de Philippe, había entregado a Joos van Wassenhove al partir para Roma en una fecha que no se hace constar ${ }^{26}$. Por una parte, este sostén financiero ha hecho suponer una protección por parte de los van der Zickele al pintor gantés; por otra, esta cronología parece entrar en contradicción con la urbinesa de entre febrero de 1473 y octubre de 1474 y una reaparición de noviembre de 1475, cronología que deberá ser explicada.

Finalmente, año y medio después, el 25 de octubre de 1474, Justo recibió la importante suma de 12.000 bolognini (300 florines de 40 bolognini) de los 250 florines de oro «a lui promessi per sua fatigha per depingere la tavola de la fraternita»; ese mismo día, en otra entrada de las cuentas, se reembolsaba esa cantidad al cofrade Guido de Mengaccio, quien se la había adelantado al pintor, señalándose entonces que a Justo se le había «da noi integramente pagato», a pesar de que «non fece al dovere», y se señalaba que se le había devengado una suma total de 600 florines (de 40 bolognini). No obstante, el método de contabilizar pagos e ingresos dificulta cualquier cómputo de la suma total entregada al artista, dado que se acumulan las partidas en las que no queda claro si el que recibe dinero es el pintor o uno de los cofrades que había adelantado a un segundo miembro de la hermandad la cantidad que le correspondía de la derrama de la pala del altar ${ }^{27}$. De esta manera, los pagos consignados el 11 de abril de 1475, cada uno a través de un hermano diferente, no corresponden - como se ha pensado tradicionalmente- con pagos al pintor, sino con arreglos de cuentas entre los distintos contribuyentes a la obra, meses después de haberse finiquitado las cuentas con el propio Justo. De hecho, la cofradía urbinesa no pagaba en tanto que institución, sino de forma personalizada a través de sus miembros y solo con carácter excepcional a través del hermano mayor o un prior; así este sería el caso de Guido da Mengaccio o, a partir de 1475, el de un nuevo miembro de la confraternidad como Bartolomeo di Nero di Brandani ${ }^{28}$, con quien nos volveremos a encontrar.

En consecuencia, Justo de Gante trabajó al servicio de la cofradía durante poco más de año y medio, entre febrero de 1473 y octubre de 1474, pues sólo reaparece el 23 de noviembre de

\footnotetext{
${ }^{25}$ La fecha de 14/15 de febrero de 1474 tiene que convertirse según nuestro cómputo moderno en 1475, dado que en Flandes se utilizaba un calendario ab Incarnatione, iniciándose el año el 25 de marzo en lugar del 1 de enero. El documento fue publicado primero por V. van der Haegen, 1910, p. 110 y nuevamente por E. Dhanens, Hugo van der Goes, Mercatorfonds, Amberes, 1998, doc. 18, p. 387, con variantes.

${ }^{26}$ «Item up de betalinghe van den jaere 75 draghende 2 lib. 10 s. gr. afgherekent Hughe den scildre 20 sch. gr. de welke de vrauwe moeder hem tachter ende sculdich was van houden reste mids dat de selve Hughe die 20 sch. gr. voor haer verleyde ende betaelde doe Joes van Wassenhove te Rome waert trac, alzo dar vrau moedren wel kenlic es». Documento de 14 de febrero de 1474 [1475] (Archivo parroquial de Saint-Michel de Gante [ahora en Archives Communales, Église SaintMichel, registro $\mathrm{n}^{\circ} 215$, fols. 45-46].

[Traducción]: «Sobre el pago del año 1475, totalizado 2 libras 10 schellingen groots [1 libra=20 schellingen] pagado a Hugo el pintor 20 schellingen groots, cantidad que la mujer [o madre de los van der Zickele] le debía por haberlos pagado Hugo en su lugar cuando Joos van Wassenhove viajó a Roma, como bien sabe la mujer». Agradecemos a Werner Thomas de la Universidad Católica de Lovaina la Nueva y Catherine Geens de la Fundación Carlos de Amberes de Madrid por su traducción.

${ }^{27}$ Sobre la mecánica de las cofradías, véase ahora Confraternities and the Visual Arts in Renaissance Italy, ed. Barbara Wisch y Diane Cole Ahl, Cambridge University Press, Cambridge, 2000.

${ }^{28}$ Urbino, Archivio della Confraternita del Corpus Domini, Libro B, 1, fol. 82, registro inédito hasta la fecha, al no haber sido transcrito por L. Moranti, 1990.
} 
1475, fecha en la que se le pagaron 9 bolognini, por una tela para «una insegna bella per la fraternita» que «Giusto depintore diceva volere [fare] a sue spese», pero que jamás llegaría a realizar. Durante este periodo de tiempo, el duque Federico da Montefeltro contribuyó a los gastos de la pintura como otro miembro más de la cofradía, aportando la suma de 15 florines.

A tenor de una entrada del 8 de marzo de 1474, se debía haber concluido ya el dibujo de la tabla, y Justo se aprestaba a dar color a la pintura, dadas la adquisición de azul ultramarino y su entrega al artista. A su vez, a tenor del documento de octubre de 1474, el maestro flamenco habría dejado inconcluso su trabajo, aunque cobrara todo el dinero que se le había estipulado en el contrato; este extraño comportamiento tendría que estar justificado por un trato de favor y que el abandono del trabajo pudiera explicarse bien por enfermedad o bien por ausentarse de la ciudad al servicio del duque. Esta hipótesis tradicional de una enfermedad y posterior fallecimiento del maestro en Urbino por estos años, podría encontrar quizá apoyo en un documento inédito, en el que un cierto «Magister Justus quondam Petri di Rosatis de partibus Alemanie habitator in Urbino», testaba el 20 de marzo de 1477, confesando encontrarse «corpore languens» $\mathrm{y}$ «timens periculum mortis», y dejando dos mandas, una a la cofradía del Corpus Domini y otra al Monte de Piedad de Urbino (Fig. 4); una precisión manuscrita del notario nos indica que el maestro había ya fallecido el 14 de septiembre de $1477^{29}$. No obstante, la presencia en Urbino y al servicio de la confraternidad, en 1472, de un segundo Maestro Giusto «racamator» [ricamatore, recamador o bordador] ${ }^{30}$, así como la existencia de una mujer Petra y una hija Luce Ugolini, hipotecan una identificación puramente mecánica, aunque no invalidan la hipótesis de la desaparición hasta ahora no documentada del pintor flamenco.

${ }^{29}$ Archivio di Stato de Urbino, Ufficcio del registro, Quadra di Posterula n ${ }^{\circ} 66$ (1477), Antonio di Simone di Antonio Vanni, 66, fo 112: «In nomine domini amen Magister Justus quondam Petri di Rosatis de partibus Alemanie d[ia] habitator Urbini sanus per gratiam domini nostri Yhesu christi mente sensu et intellectu licet corpore languens timens periculum mortis cum nihil sit certius mortis et nihil incertius hora mortis nolens intestatus decedere suarum rerum et bonorum omnibus dispositionem in hinc modi facere procuravit et fecit per praesens nuncupatum testamentum quod dicitur sine scriptis.

In primis quidem jussit et voluit cum eum mori contingerit suum corpus sepellire apud eclesiam sancti francisci de Urbino apud quam suam sibi ellegit sepulturam cui eclesie reliquit iure legati pro anima sua florines decem ad rationem $\mathrm{xl}$ bolognini pro florino pro fabrica et reparatione dicte eclesie. Item reliquit fraternitati disciplinatorum corporis christi unam pars dupleriorum ponderis quatuor librarum dicto iure.

Item reliquit pro anima ipsius testatoris iure legati monti pietatis civitatis Urbini bolognini viginti.

In omnibus autem aliis suis bonis mobilibus et inmobilibus propris et enfiteuticis iuribus et actionibus presentibus et futuris ubicumque sunt et reperii possunt et potuerit suam heredem universalem instituit et fecit pleno iure do[mi]nam Petram eius uxorem et filiam quondam Luce Ugolini.

Et hanc suam ultimam voluntatem afferunt dictus testator esse quam valet. Voluit iure testamenti et si iure testi non valeret seu non valebit valere voluit iure codicillorum vel alterius cuius cumque ultime voluntatis quem melius valere possit potuit et tenere cassans iuritans[?] et anullans omnem aliud testamentum et omnem aliam ultimam voluntatem per ipsium testatorem primum[?] factam et factam quibus omnibus voluit hoc praesens testamentum pro... implectam facta processis et nullis his eis.

Actum factum conditum et afirmatum sint dictum testamentum per dictum testatorem in civitatis Urbini et in domo ipsius porta in burgo... ... supra viam publicam ab uno latis Bona Laurenti et Iacobi ab alio et alia latis. Et scriptum et lectum et publicatum per me Antonium notarium infrascriptum sub annis domini ab eius nativitate millessimo cccclxxvii indictionem decima tempore santissimi in Christo Patris et domini domini Sixti divina providentia pape quarti die ultima mensis martii presentibus Nicolao Avanzoli Petri Antonio Bartoli Vagnini ser Francesco Arcangeli de Urbino Magistro Johane alias [cognomine] Pelicione Arigi de partibus alemanie Francesco magistri Leoncini et Juliano cognomine il pellato Marini Bechario et Johanes donini Francesci de Urbino testibus ad hoc vocatus habitis ore proprio dicti testatoris vocatis et rogatis.

Et ego Antonius ser Simonis de Antonii de Urbino et quadra Posterula publicus imperiale auctoritatis notarius ordinationi et confectioni dicti testamenti et omnibus et singulis predictis praesens fui dum sic ordinaretur et... ea rogatus [?] scripsi et publicavi signum meum conscretum apposui.

Ditto millessimo die xiiii mensis septembris decessit dictus testator quod notificatum fuit michi notario.

Die vero xviii mensis autenticavi et ceheras[?] restitui.

Ditto Millessimo et die xx dictis mensis septembri praesens instrumenti presentibus fuit et civitatis Urbini... et ditta die.... per me Thomas Lodovicus de Urbino notarius dictus...

Et ego Thomas Lodovicus de Urbino et de quadra scrivanus publicus imperiale michi notus».

${ }^{30}$ L. Moranti, 1990, p. 216.

AEA, LXXV, 2002, 300, pp. 361 a 380 

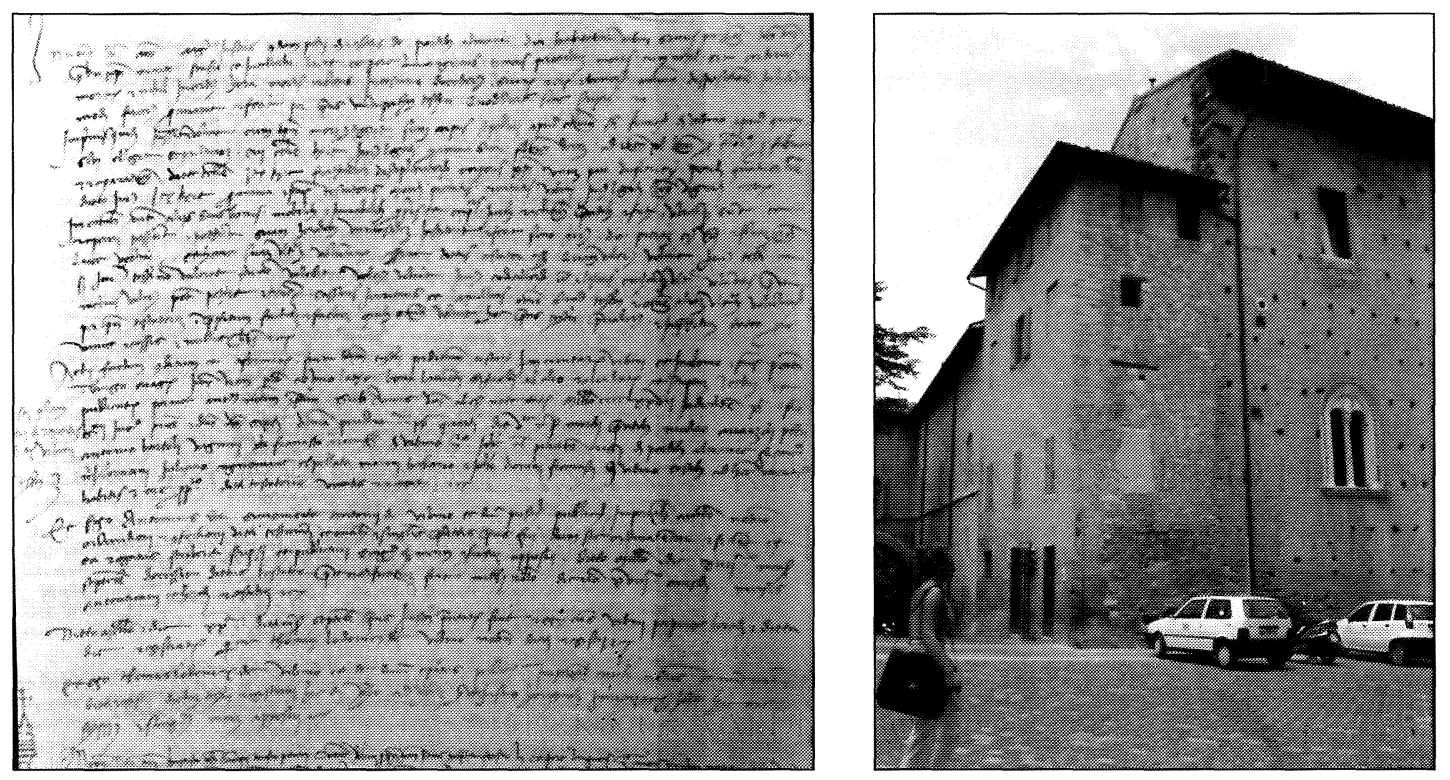

4

5

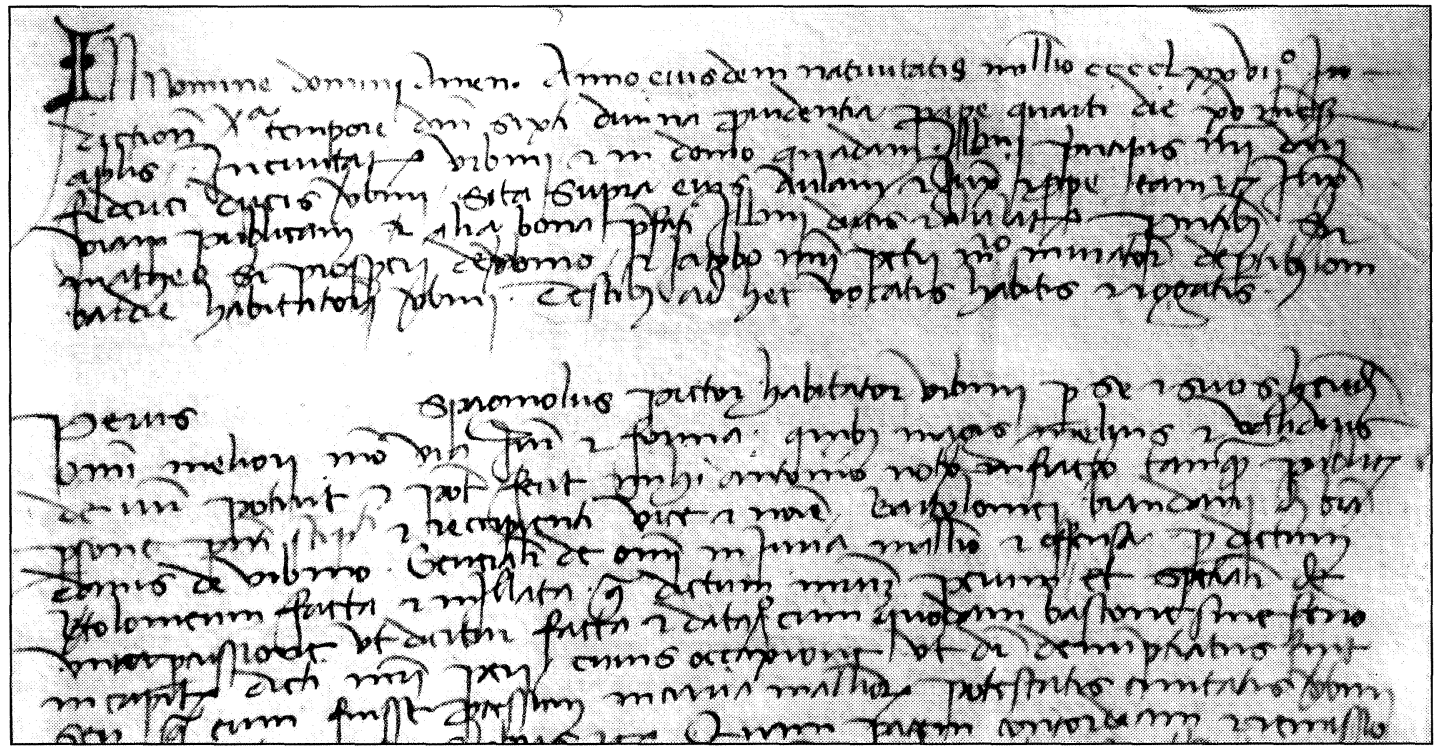

Fig. 4. [JustoUrbino] = Documento de Maestro Giusto, en Archivio di Stato di Urbino, Ufficcio del registro, Quadra di Posterula $n^{\circ} 66$ (1477), Antonio di Simone di Antonio Vanni, 66, $\mathrm{f}^{\mathrm{D}} 112$.

Fig. 5. [Petrus Hispanus] = Documento di "Perus Spagnuolus", en Archivio di Stato di Urbino, Antonio di Simone di Antonio Vanni, $44, \mathrm{f}^{\circ} 201$

Fig. 6. [Petrus Hispanus] = Urbino, Palazzo Ducale, ángulo sureste. 
La segunda hipótesis podría apoyarse en la relación de servidumbre entre el pintor y el duque, a quien pudo haber seguido en el otoño de 1474 en su estancia en Roma y Nápoles, cuando se desplazó para recibir la orden del Armiño (Ermellino) de los Aragoneses de Nápoles, y pudo entonces haberle encargado que retratara a Sixto IV, cuya efigie fue incluida precisamente en estas fechas en el programa de los uomini illustri del studiolo de Urbino.

Con independencia de su hipotética muerte entre 1474 y 1477, el alcance de la responsabilidad material de Justo en «La Comunión de los apóstoles» queda todavía indefinida. Por una parte, no habría tenido tiempo de concluirla como se esforzaron en señalar por escrito los cofrades; por otra, parece que durante 1475-76 la cofradía dio los trabajos por terminados al pagar una cortina y sus anillas con la que proteger la obra. Otra posibilidad, jamás tenida en cuenta, y que podría tener fundamento en el análisis de la superficie pictórica, es que la tabla jamás llegara a terminarse, con independencia de que un segundo maestro (Petrus Hispanus) la diera injustificadamente por concluida hasta el extremo de colocar su firma ${ }^{31}$.

El problema de la conclusión de la pintura de la tabla nos devuelve, por lo tanto, a la misteriosa firma del artista «Petrus Hispanus» reproducida por Gabriel Naudé en su dibujo, cuando todavía era perfectamente legible. Sin embargo, contra toda lógica dada la minuciosidad de la contabilidad de la cofradía, el nombre del pintor español brilla soprendentemente por su ausencia en las páginas del Libro B,1, única fuente documental conservada ${ }^{32}$. Una de las paradójicas consecuencias de este dibujo seicientista es que la única pieza documentada de toda la obra pictórica de Justo de Gante aparezca apropiada por otro artista, cuya personalidad es huidiza y cuya misma existencia ha sido negada.

\section{Un documento reencontrado y otras noticias de archivo}

Una segunda consecuencia del citado dibujo sería la prueba de la presencia en Urbino de este «pintor español», al cual se le daba en 1632 por primera vez un nombre, «Petrus». Por lo tanto, corroboraba la noticia que Luigi Pungileoni dio a conocer en 1822, en la que de forma lacónica señalaba la mera existencia de un «Pietro Spagnuolo pittore» junto a la referencia notarial «Rog[ito]. Simone di Antonio Vanni 1477. Aprile 14» ${ }^{33}$.

A pesar de tal puntualización, el documento jamás ha vuelto a ser encontrado, aunque el wishful thinker (en palabras de Cecil H. Clough) José Allende-Salazar afirmara en 1927 haber tenido el documento entre sus manos en el citado protocolo y no entender su grafía, para prometer una transcripción futura que nunca llegó a publicarse ${ }^{34}$; parece evidente, como veremos, que el diplomático español jamás tuvo ante sus ojos el citado documento - ya que de haberlo visto no hubiera podido citarlo de otra forma y de haberlo leído haber dado cuenta de su sorprendente y cómico contenido- aunque pudiera tener entre sus manos la filza del citado y a la

\footnotetext{
${ }^{31} \mathrm{El}$ aspecto inconcluso de la tabla supuestamente al óleo podría haber llevado a Gabriel Naudé a tomarla como una pintura (a guazzo) al temple.

Por otra parte, es posible que la figura del niño Guidobaldo en brazos de una nodriza pudiera haber solo seguido la inscripción del mismo como cofrade, hecho que solo tuvo lugar el 9 de junio de 1475 . No obstante, nacido el 24 de enero de 1472, podría aparentar una edad menor y más próxima a la cronología de la estancia urbinesa (diciembre de 1472-enero de 1473) del embajador del Shah de Persia el médico judío español Isaac, convertido en Roma y bautizado como Sixto por el papa Sixto IV, episodio que parece quedar reflejado en una tabla que se comenzaría inmediatamente después. Sobre tales hechos, véase M. Aronberg Lavin, «The Altar of Copus Domini in Urbino: Paolo Uccello, Joos van Ghent, Piero della Francesca», The Art Bulletin, 49, 1967, pp. 1-24.

${ }^{32}$ Agradecemos al Dr. Giuseppe Cucco, hermano mayor de la Confraternita del Corpus Domini, sus facilidades para la consulta de esta documentación, como vemos solo parcialmente publicada por Lavalleye y Moranti.

${ }^{33}$ L. Pungileoni, 1822 y 1994 , p. 49.

${ }^{34}$ J. Allende-Salazar, «Pedro Berruguete en Italia», Archivo Español de Arte y Arqueología, 8, 1927, pp. $133-138$.
}

$A E A, \mathrm{LXXV}, 2002,300$, pp. 361 a 380 
postre erróneo notario. En consecuencia, nuestra opinión es que Allende-Salazar —en un verdadero caso de wishful thinking - nunca alcanzó a ver este escurridizo documento de Pungileoni.

No es de extrañar que Clough, después de comprobar que no se encontraba tal documento en ese mismo rogito del notario Simone di Antonio Vanni, y de constatar asimismo la existencia de una familia urbinesa apellidada «Spagnolo» ${ }^{35}$, juzgara como un claro ejemplo de buenos deseos el afán de la historiografía española por reconocer la mano de un pintor de esta nacionalidad entre los encargos de Federico da Montefeltro; tampoco puede extrañar que llegara, incluso con mayor razón, a poner en duda la identificación del tal Pietro Spagnolo con el pintor castellano Pedro Berruguete ${ }^{36}$, el artista activo después en Castilla entre 1488 y 1503, y de cuya formación italiana no existen otras pruebas que las que se desprenden del análisis filológico de la obra documentada y de la generosamente atribuida en su fluctuante catálogo.

No obstante, el documento existe en el Archivio di Stato de Urbino (Fig. 5). La razón para que no haya sido reencontrado se debe a un sencillo pero trágico error de Luigi Pungileoni, pero también al optimismo de la historiografía española que ha dado hasta hoy por buena la noticia de Allende-Salazar, a pesar de su promesa «incumplida», y se ha mostrado impasible ante cualquier género de duda razonable, como la expresada por Clough. Pungileoni confundió al notario Simone di Antonio Vanni con su hijo y también notario de la Quadra Posterula de Urbino Antonio di Simone di Antonio Vanni ${ }^{37}$. En el protocolo de 1477 de este último notario, el 15 de abril, se recogió la comparecencia de un cierto «Magister Perus», cuyo apellido se deja en blanco para solo añadirle un topónimo «spagnuolus» y su profesión de «pictor» ${ }^{38}$.

Este pintor, que aparece como «habitator Urbini» y al que en consecuencia habría que suponerle una estancia en la ciudad de al menos un lustro, de acuerdo con los usos legales allí vigentes, ocupaba una habitación «in domo quadam [sic] Illustrisimo principis nostri domini federici ducis urbini sita supra eius aulam iuxta et prope tam iuxta viam publicam», es decir residía en la zona meridional del palacio como miembro de la servidumbre ducal (Fig. 6). En presencia de dos testigos - el notario Matteo di ser Prosperi y el maestro muratore (maestro de albañilería o incluso aparejador) lombardo Jacopo di Mastropietro- este documento nos evidencia unas circunstancias y nos narra una historia.

En primer lugar, hallamos a Piero Spagnolo domiciliado en el espacio palaciego reservado al servicio de la corte, y por lo tanto como un asalariado del duque como pintor; no obstante, nuestro maestro se hacía acompañar de un notario y un maestro de albañilería del palacio, hasta ahora completamente desconocido ${ }^{39}$, más que por su arquitecto.

Algunos meses atrás, y sin que se nos especifique la causa, Magister Perus había sido víctima de una agresión por parte de Bartolomeo Brandani de Brandani, personaje que hemos de identificar con el ya citado cofrade del Corpus Domini. Éste le había golpeado («unam percusione $[\mathrm{m}] »$ ) en la mismísima cabeza, y nada menos que con un bastón de hierro («cum quodam bastone sive ferro in capite dicti magistri peri»), con resultados cuya gravedad des-

\footnotetext{
${ }^{35}$ A los citados por Clough, podría añadirse el caso del Beato Pietro Spagnioli († 24 de junio de 1415), eremita jerónimo en la zona del futuro monasterio de San Bernardino de Urbino, que había vivido en sus últimos años en el oratorio de San Giovanni, en cuyo altar mayor todavía se conserva su cuerpo.

${ }^{36} \mathrm{C}$. H. Clough, «Pedro Berruguete and the Court of Urbino: A Case of wishful Thinking», Notizie di Palazzo Albani, III, 1, 1974, pp. 17-24, y en The Duchy of Urbino in the Renaissance, Variorum Reprints, Londres, 1981, pp. X, 1-13.

${ }^{37}$ Archivio di Stato de Urbino, Antonio di Simone di Antonio Vanni, 44 (1477), $\mathrm{f}^{\circ} 201$. Reiteramos nuestro agradecimiento a Don Franco Negroni por sus indicaciones para el hallazgo del documento, y al Dr. Leonardo Moretti por su ayuda en la transcripción del mismo.

${ }^{38}$ Véase la transcripción completa del documento en Apéndice.

${ }^{39}$ Véase Francesco Paolo Fiore, «Urbino», en Storia dell'architttura italiana. Il Quattrocento, ed. F. P. Fiore, Electa, Milán, 1998, para la bibliografía más reciente sobre el palacio.
} 
graciadamente se nos escapa; tampoco se nos informa de los motivos de una disputa que terminó violentamente, aunque los vínculos de ambos - como veremos - con la confraternidad del Corpus Domini, hacen posible que el origen de la discusión se encontrara relacionado con la ejecución de la tabla de su altar mayor; por otro lado la disensión pudo haberse quizá agravado a causa de dos temperamentos tal vez fogosos, el de un miembro de la casta militar de Urbino y el de un artesano orgulloso de su condición de hidalgo. Ante tan ofensiva agresión por parte de un personaje de rango superior, Magister Perus no habría podido sino tramitar la correspondiente denuncia ante la justicia de Urbino («in curia maleficiorum potestatis civitatis Urbini») contra el citado Bartolomeo Brandani ${ }^{40}$.

El agresor, además de cofrade, era un notable miembro de la nueva aristocracia local, a quien otros documentos urbineses dan el tratamiento de «egregius vir», y aparece en numerosas ocasiones como testigo y otorgante en instrumentos notariales de carácter fundamentalmente económico, fechados entre al menos 1473 y $1484^{41}$. De acuerdo con un documento de $1479^{42}$, Bartolomeo era hermano de Giovanni Antonio Brandani di Brandani, nada menos que gonfaloniere del ducado de Urbino, padre de los dos importantes militares urbineses Bonaventura y Scipione, como es sabido constructores de sendos palacios en la ciudad, uno de ellos hoy desaparecido ${ }^{43}$.

Bartolomeo Brandani, quien no estuvo presente en el acto protocolizado, recurrió a otra via, extrajudicial, para resolver el pleito con el pintor español, llegando al acuerdo de que éste retirara la denuncia a cambio de la importante cantidad de 25 libras (200 florini). El siguiente 30 de abril de 1477, el notario dio cuenta de que la suma había sido ya entregada al ofendido - cuya gravedad se nos escapa al desconocer los hábitos urbineses de compensación en estos casos - y el litigio había quedado resuelto, aunque de forma quizá ingrata para quien se tenía por hidalgo castellano.

El dibujo publicado por Vladimír Juřen y los nuevos documentos notariales de Urbino, que nos hablan de un Perus o Petrus Spagnuolus o Hispanus, confirman la presencia de un pintor de origen español en la Urbino de la década de 1470, trabajando aparentemente al servicio del duque como vecino de la ciudad y residente en el palacio ducal. Dibujo y documentos vienen a establecer un vínculo estrecho, al mismo tiempo, entre Justo de Gante y el pintor español, dado que contemporáneamente se encontraban trabajando en el mismo lugar y para los dos mismos clientes, la confraternita y Federico da Montefeltro.

${ }^{40}$ No parecen haberse conservado los registros de la justicia montefeltriana del siglo xv (entre los fondos del actual Archivio di Stato di Firenze), que habrían permitido seguir la pista a este proceso y clarificar sus causas, que desgraciadamente quedan todavía en la oscuridad; sobre los avatares del archivo ducal de Urbino, véase A. D'Addario, «L'Archivio del Ducato di Urbino - Un problema di storia e di diritto archivistico», Miscellanea in memoria di G[iorgio]. Cencetti, Turín, 1973, pp. 579-637. Sobre los procedimientos judiciales contemporáneos, Laura Ikins Stern, The Criminal Law System of Medieval and Renaissance Florence, The Johns Hopkins University Press, Baltimore, 1994.

${ }^{4}$ S.A.S.U., Antonio di Simone di Antonio Vanni, 44, fo 45 -[28-III-1473], como testigo; Antonio di Simone di Antonio Vanni, 44, fo 65: [21-XI-1473], como testigo; Antonio di Simone di Antonio Vanni, 44, fo 128: [11-I-1476], como testigo; Antonio di Simone di Antonio Vanni, 44, fo 278-279: [20-III-1479], en el contrato de compraventa de una casa; Archivio di Stato de Urbino; Antonio di Simone di Antonio Vanni, 44, fo 357: [29-V-1480], como testigo; Antonio di Simone di Antonio Vanni, 44, fo 368; Antonio di Simone di Antonio Vanni, 44, fo 375-375 vo: [19-XII-1480], testigo de «Angelus magistri Antonioli faber bergamascus habitator urbini...»; Antonio di Simone di Antonio Vanni, 44, $\mathrm{f}^{\mathrm{o}}$ 403: [21-VII-1481], como testigo; Antonio di Simone di Antonio Vanni, 44, f ${ }^{\circ}$ 407: [21-VII-1481] testigo de un préstamo; Vescovado 66 (1483), $\mathrm{f}^{\mathrm{o}} 32 \mathrm{v}^{\mathbf{o}}$ : [14-VI-1483], citado en un documento del monasterio de San Benedetto de Urbino como «egregio viro Bartolomei Brandani Bartolomei de Brandanis de Urbino...»; Vescovado 67 (1484), f 24: al margen: «Egregio Viro Bartholomei de Brandanis de Urbino».

${ }^{42}$ S.A.S.U., Antonio di Simone di Antonio Vanni, 44, fo $278-279$ (20-III-1479).

${ }^{43}$ Sobre el gonfaloniere y su familia, véase Archivio dell'Universitá, Busta $171, \mathrm{n}^{\circ} 21$, con una brevísima semblanza de los Brandani, cuyo árbol genealógico comienza precisamente con la figura de Giovanni Antonio, gonfaloniere al menos desde 1477. Sobre sus hijos, véase A. Lazzari, Discorsi, Fermo, 1796, pp. 174-175. Sobre los palacios, F. Mazzini, Urbino. I mattoni e le pietre, Urbino, Comune di Urbino, 20003, pp. 276-278.

AEA, LXXV, 2002, 300, pp. 361 a 380 
Justo de Gante y Piero Spagnolo: nuevos problemas

A las dificultades ya citadas de la identificación de Justo y Joos van Wassenhove (Joos van Ghent más que el improbable Giusto di Gualtieri di Guante), y a las tradicionales y todavía no resueltas dudas con respecto a su obra en Flandes, hay que añadir el de su propia participación en las tablas de Urbino. El dibujo de Naudé y nuestros documentos tienden a reforzar la hipótesis de una relación de taller, al encontrar al español viviendo en el palacio ducal y no comparecer en su documento de perdón el maestro Justo, situación que reforzaría la idea de un óbito anterior a 1477 o de este mismo año. Si ponemos todos estos datos en una secuencia cronológica, la única teoría compatible con todos ellos, y con el «sentido común», sería la de la desaparición del maestro responsable del taller en un momento intermedio en la factura de todas las tablas, de la cofradía y del studiolo, y que quedara como responsable de su conclusión su oficial español.

En el primero de los casos, éste llegaría al extremo de firmar la obra de Justo apropiándosela con su rúbrica. Estos hechos solo son inteligibles de haberse dado entre Justo y Piero una colaboración asimétrica en un taller, que además podría justificar la falta de documentos de carácter económico de Piero y la siempre extraña aparición tardía de su firma sobre la tabla inconclusa de la confraternita del Corpus Domini.

Mientras tanto, ante el problema de la atribución de las tablas de los uomini illustri del studiolo, nos hallaríamos ante la dirección del pintor flamenco, asistido por el español en términos subordinados cuyo alcance todavía es susceptible de debate, tal como ha establecido el más reciente análisis técnico y formal de las tablas del Musée du Louvre ${ }^{44}$. En concordancia con este estudio de Nicole Reynaud y Claudie Ressort, a nuestro juicio solamente habría por ahora que señalar la presencia añadida de un tercer maestro, claramente italiano, cuya responsabilidad se extendería quizá a otras obras, desde el retrato doble de «Federico y Guidobaldo da Montefeltro» de Urbino, las Alegorías de las Artes Liberales de Berlín y Londres, y la «Lección» de Hampton Court ${ }^{45}$. En continuidad con esta tesis, la eventual muerte (septiembre) del citado Maestro Giusto en 1477 y la fecha de su testamento (marzo) coincidirían con la cronología de la llegada a Urbino y Gubbio (mayo) y la entrada al servicio ducal (noviembre de 1477) de Francesco di Giorgio Martini (1439-1501).

A este respecto, la última virtud de la hipótesis que venimos manejando es la de hacer coincidir los datos técnicos con los biográficos: la existencia de dos manos diferentes y de importancia asimétrica y la copresencia de dos personajes en momentos muy distintos de sus vidas y capacitación y trayectorias profesionales.

Además, otros dos hechos ratifican la colaboración de un pintor español en el studiolo urbinés. Por una parte, como se ha señalado desde antiguo, la lengua empleada en la inscripción del libro que sostiene en sus manos San Alberto Magno, en el que se han podido leer unos fragmentos en castellano: «mundo malo mundo fal(so) / de todo bien me... / quien trae... / mira hurtado... / trae grande... / ... (por) ande / porque... /... « (Figs. 7-8). Francisco Javier Sánchez Cantón identificó años atrás estos versos con los de un poema del I Marqués de Santillana don Íñigo López de Mendoza, extraídos de su Doctrinal de privados fecho a la muerte del Maestre de Sanctiago don Álvaro de Luna ${ }^{46}$, con el que, sin embargo, solo coincide una estrofa: «¿Qué

\footnotetext{
${ }^{44}$ N. Reynaud e C. Ressort, «Les portraits d'hommes illustres du studiolo d'Urbino au Louvre par Juste de Gand et Pedro Berruguete», Revue du Louvre, xli, 1991, pp. 82-113.

${ }^{45}$ Para un état de la question, véase ahora O. Raggio y A. M. Wilmering, The Liberal Arts Studiolo from the Ducal Palace at Gubbio, New York, The Metropolitan Museum of Art, 1996, y The Gubbio Studiolo and Its Conservation, 2 vols., New York, The Metropolitan Museum of Art, 1999.

${ }^{46}$ F. J. Sánchez Cantón, «Recensión de Jacques Lavalleye, «Just de Gand ou Pedro Berruguete», en Bulletin de l'Institut Historique Belge de Rome, xiii, 1933, pp. 3-14, Archivo Español de Arte y Arqueología, ix, 1933, pp. 146-148. Nuestras consultas a varios especialistas para localizar la fuente de tal texto han sido infructuosas.
} 

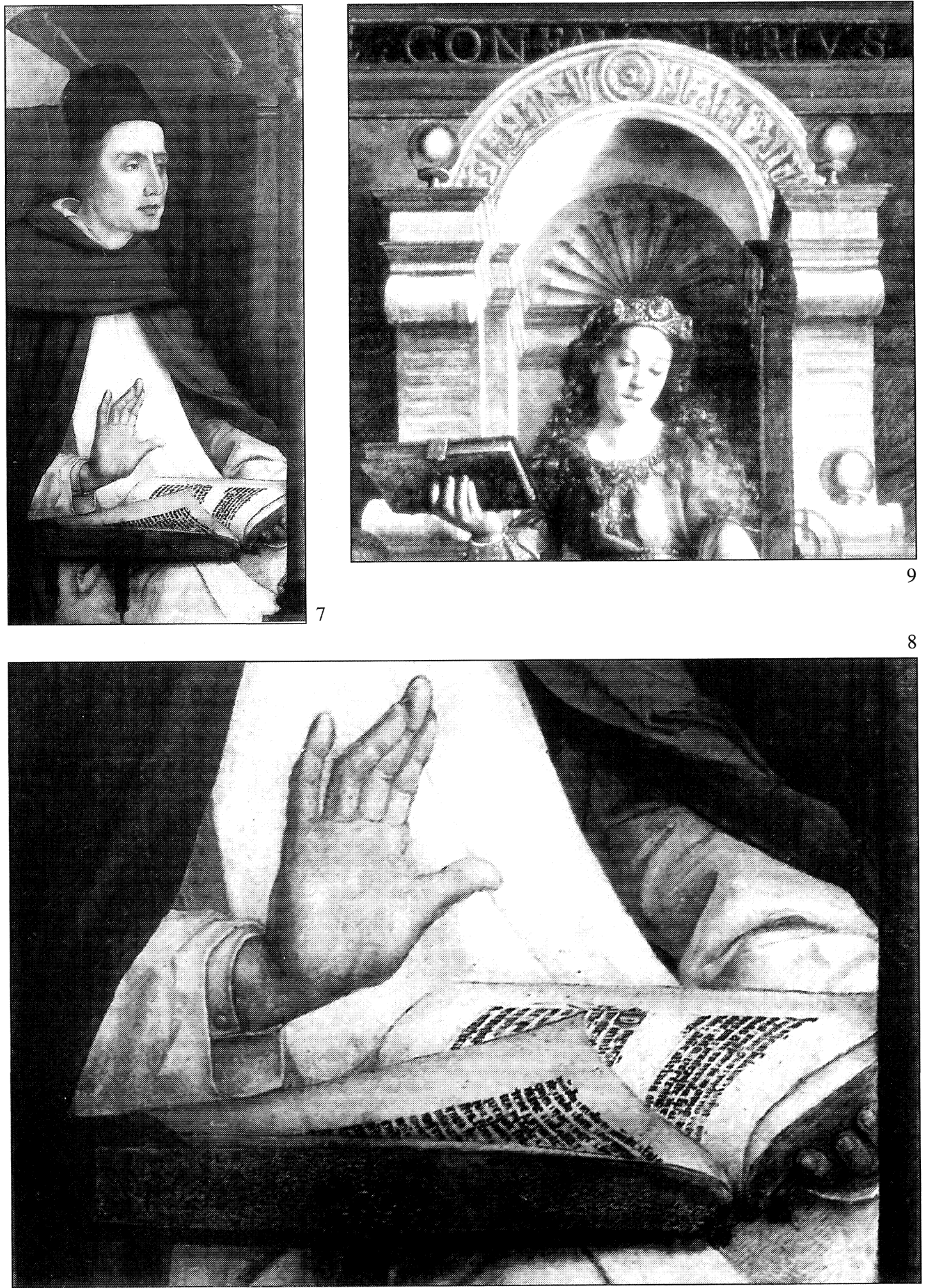

Fig. 7. [Urbino S. Alberto] = San Alberto Magno, París, Musée du Louvre

Fig. 8. [Urbino S. Alberto, detalle] = San Alberto Magno, París, Musée du Louvre, detalle.

Fig. 9. [Petrus Hispanus] = Alegoría de la Música, Londres, National Gallery of Art, detalle.

AEA, LXXV, 2002, 300, pp. 361 a 380 
le fizo la moneda / que guardé para mis damas / tantos tiempos tantos daños? / Plata joyas oro e seda / ca de todo no me queda / sinon este cadahalso / mundo malo mundo falso / non es quien contigo pueda» ${ }^{47}$.

Por otra parte, una segunda inscripción, en esta ocasión en lengua árabe y en carácteres correctos cúficos nasrid, merece ser tenida en cuenta ahora por vez primera; aparece en el remate semicircular de la cátedra de la «Música» de la National Gallery of Art de Londres, como si hubiera sido tomada de la inscripción de un plato de cerámica dorada de los talleres valencianos de Manises (Fig. 9); transcribe correctamente en términos gráficos fragmentos de frases en alabanza de Allah pero de forma ilógicamente entrecortada, constituyendo por lo tanto un conjunto en sí mismo incomprensible, que excluiría cualquier conocimiento de la lengua árabe por parte del pintor ${ }^{48}$, al que en cambio esta cultura no resultaría completamente ajena. Esta cerámica constituía en la Europa cristiana de la época un objeto frecuente del comercio suntuario, y es muy posible que Federico da Montefeltro hubiera poseído algún ejemplar de tal tipo de cerámica, del que se conservan todavía restos en la Galleria Nazionale delle Marche, que sirviera de fuente para la inscripción del citado trono, con la intención - hemos de suponer- de conferir a la Música un sentido orientalizante, que pudiera servir de referente a una tradición que identificaba el Canto o la Música con el mundo oriental, mosaico, a través de su mítico inventor el bíblico Tubalcaín.

Al margen de estos dos indicios, no es posible identificar en esta serie de obras otros elementos vinculados a una cultura visual española, ya sean rasgos estilísticos u otros cualesquiera componentes de una formación hispana. Esta doble constatación - un español sin rasgos artísticos exclusivos de lo hispano- debiera obligarnos a replantear el «problema Berruguete» en términos muy distintos a los que estamos acostumbrados a encontrar. Si la historiografía española se ha contentado con la mecánica identificación del pintor español de Luigi Pungileoni con Pedro Berruguete, no menos mecánica ha sido su identificación del conjunto del arte del castellano con un simplista «Renacimiento», congratulándose de haber hallado en él la figura con la que desembarcarían en Castilla los nuevos modos de la pintura renacentista, y encontrado en él la cabeza de serie de la pintura española moderna e internacional, de la que paradójicamente se convertía en conspicuo representante. Y decimos de forma paradójica pues, a pesar de su formación mixta entre el modelo flamenco y el italiano, la crítica tradicional ha identificado como hemos visto en su pintura los más evidentes rasgos de la «españolidad»—léase de entrada realismo- de nuestra «escuela pictórica nacional».

Frente a esta tradición, los dos descubrimientos ante los que nos enfrentamos hoy, aunque no resuelven el «problema Berruguete», sí introducen, desde una diferente complejidad, una nueva plataforma para la discusión, a partir de la que deberán impostarse los estudios tanto sobre Wassenhove como sobre Berruguete. En estos momentos pueden identificarse como problemáticos, e inexorablemente interrelacionados (como para no poder resolverse de forma aislada contra los hábitos recibidos), los siguientes temas. En primer lugar, la ubicación de $P e$ trus Spagnuolus en Urbino no podrá sustraerse de los estudios polémicos sobre Justo de Gante y Joos van Wassenhove, dadas las contradicciones entre la supuesta dependencia del español con respecto al flamenco que nos presenta la documentación urbinesa y las deducciones que

\footnotetext{
${ }^{47}$ C. H. Clough, 1974, ha supuesto que el texto castellano podría estar justificado por el enfrentamiento entre San Alberto y Averroes y, por otra parte, que se hubiera tomado la cita de uno de los dos manuscritos castellanos que sabemos existían en la biblioteca ducal de Urbino: «Liber hispana lingua. de modo pugnandi quint. 4. [e] Libellus cum cantilenis hispanis solphatus et ornatus», de casi imposible identificación; según esta interpretación, no habría sido necesaria la presencia de un español para pintar este texto, copiado de un manuscrito ducal. Tampoco ha sido posible la identificación de tales manuscritos a pesar de los intentos realizados.

${ }^{48}$ Agradecemos a la Profesora Carmen Bravo Villasante, del Departamento de Árabe de la Universidad Autónoma de Madrid, por sus preciosas precisiones al respecto.
} 
se han realizado sobre la formación artística de Berruguete ${ }^{49}$, y la convergencia por otra parte de sus itinerarios antes de llegar a Italia o antes de alcanzar la ciudad de Urbino, tras una hipotética presencia de ambos en Roma ${ }^{50}$. En segundo lugar, todavía es imprescindible avanzar en la definición de los términos de la colaboración entre ambos artistas en el ámbito del taller de Urbino, así como el análisis de la trayectoria independiente de Berruguete, tras la desaparición de Justo, y antes de su regreso a España. Frente a la simplificadora reconstrucción biográfica que lo hacía llegar a Toledo (1483) inmediatamente después de la muerte (1482) de Federico da Montefeltro, se debería tener en cuenta una salida previa de Urbino y una permanencia en Italia hasta la fecha de 1488, en la que se le documenta por vez primera en España. Por descontado, se debería replantear la propia carrera española de Berruguete, que no sólo tenga cuenta de su estancia y cronología urbinesa para explicar el aggiornamento de sus relaciones con el mundo italiano a partir de 1488 .

\section{Toledo 1483/1488: una precisión documental}

La fecha del primer documento probatorio de su regreso a España, uno de los datos fundamentales para la construcción de la biografía de Pedro Berruguete, continúa siendo también objeto de debate ${ }^{51}$. No obstante, como en tantas otras ocasiones, es demostrable que un simple error de lectura de un documento ha hecho arrastrar un equívoco que creemos poder disipar tras revisar de nuevo los fondos documentales de la Obra y Fábrica y el Archivo Capitular de la catedral de Toledo.

Es necesario tener en cuenta dos elementos; por una parte, los propios documentos; por otra, la historia de su transmisión desde el siglo xviII a nuestros días. Esta última comienza en 1800 con la biografía del pintor incluida en su Diccionario por Juan Agustín Ceán Bermúdez, donde escribió ${ }^{52}$ : «El año de 1483 se encargaron las pinturas de las paredes del Sagrario viejo a maestre Antonio (que sospecho fuese Antonio del Rincón) y a Pedro Berruguete, natural de Paredes de Nava, como dice el asiento; pero habiéndose suspendido esta obra el mismo Berruguete hizo obligación en 17 de julio de 1488 de acabar de pintar todas las historias que faltaban debaxo de la primera orden de las trabajadas por su mano y de la de Maestre Antonio por el precio de 75.000 maravedís de la moneda usual».

Por tanto, en su opinión, Berruguete estaría documentado con Maestro Antonio ya en 1483, y así lo «repetirán» los documentalistas por excelencia de la catedral, el dieciochesco canónigo don Francisco Pérez Sedano (1914) y el más tardío don Manuel R. Zarco del Valle (1916) ${ }^{53}$, quienes realizaron un importante vaciado de los fondos documentales de los libros de cuentas de la Obra y Fábrica toledana.

\footnotetext{
${ }^{49}$ Contra toda la tradición historiográfica, defendiendo una formación sólo española, P. Silva Maroto, Pedro Berruguete, Salamanca, Junta de Castilla-León, Salamanca, 1998, quien identifica sin reservas el artista palentino y el pintor activo en Urbino.

${ }^{50}$ Desde el libro de August Schmarsow, Joos van Gent und Melozzo da Forli in Rom und Urbino, Abhandlungen der philologisch-historischen Klasse der Königlich Sächsischen Gesselschaft der Wissenschaften, XXIX, vii, Leipzig, 1912, hasta la reciente exposición, Melozzo da Forli. La sua città e il suo tempo, ed. Marina Foschi y Luciana Prati, Leonardo Arte, Milán, 1994, permanece abierta la discusión sobre obras atribuibles a Justo de Gante en Roma, en concreto en la basílica de San Marco.

${ }^{51}$ A pesar de la revisión documental de F. Marías, 1989, véase lo mantenido por P. Silva Maroto, 1998,2001 y 2002.

52 J. A. Ceán Bermúdez, Diccionario histórico de los más ilustres profesores de las Bellas Artes en España, Madrid, 1800,I, pp. $145-146$.

${ }^{53}$ F. Pérez Sedano, Datos documentales inéditos para la Historia del arte español. Notas del archivo de la catedral de Toledo, Madrid, 1914, pp. 10-11; M. R. Zarco del Valle, Datos documentales para la Historia del Arte Español. Documentos de la catedral de Toledo, Madrid, 1916, I, p. 21.
}

$A E A, \mathrm{LXXV}, 2002,300$, pp. 361 a 380 
No obstante, parece haber pasado desapercibido el hecho de que la fuente de Ceán es el propio Pérez Sedano, como declaraba aquél en el prólogo de su Diccionario, y que manejó un cuaderno de notas que es precisamente el que fue publicado por Elías Tormo ${ }^{54}$; en consecuencia, la fuente única de la información es la de Pérez Sedano, repetida de forma mecánica hasta 1989. Como después Ceán, el canónigo vinculó en un párrafo dos diferentes noticias: «Después se pintó el Sagrario por maestro Antonio y Pedro Berruguete, natural de Paredes de Nava, en el año de 1483; y posteriormente hizo Berruguete obligación de acabar todo el Sagrario en 17 de julio de 1488, cuya obligación se conserva en la obra».

La segunda noticia vinculada por Pérez Sedano corresponde, por lo tanto, a un contrato de 1488 hoy ilocalizable, pero al que se refieren otros documentos de pago al pintor palentino; en cuanto a la primera, procede de las cuentas de los Libros de Fábrica - de donde los toma, como la mayoría de sus datos siempre que no hace referencia a un documento independiente- $\mathrm{y}$ en este caso afortunadamente se conserva dicho Libro de cuentas del bienio 1483-84 (ACTOF 788). A lo largo de las páginas del mismo, se encuentran efectivamente diversos pagos a Maestro Antonio por la ejecución de esta obra, así como otros a Pedro Becerril, que transcribimos en su integridad:

[fol. $44 \mathrm{v}^{\circ}$ ] «Yten que dio e pagó a Pedro Becerril pintor en veynte e ocho de junio (28VI-1483) porque fue a Villanueva de los Ynfantes a comprar azul por su mandado del dicho señor obrero para la pintura del Sagrario el qual truxo dies e syete libras e tres onças de azul que allá compró a diversos presçios porque no hovo todo ygual nyn falló más con la costa que allá fizo en yda y venyda quatro myll e setecientos e doze maravedís y medio $\left(4.712^{1 / 2}\right)$ ».

«Yten que se compraron por mano de Maestre Antonio pintor de Andrea de Mar ginovés syete libras e media de azul ultramarino para la dicha pintura del Sagrario a raçón de seyscientos maravedís cada libra que montaron quatro myll e quinientos maravedís (4.500)».

«Yten que dio e pagó al dicho Maestre Antonio pintor por una libra e catorze onças de azul fino que ...nýa seyscientos y veynte maravedís (620)».

«Todo este azul se entregó a Maestre Antonio pintor para fazer la dicha pintura del Sagrario».

«Yten que dio e pagó por dos libras de azul que se compraron de Martín Suárez (?) para el Sagrario quatrocientos maravedís (400) que se dio a Maestre Antonio».

[fol. $76 \mathrm{v}^{\circ}$ ] «Yten que costaron tres paletas de hierro que mandó fazer Maestre Antonio pintor para el asyento del betuín de la pintura del Sagrario a veynte e cinco maravedís cada una tres ástiles para ellas que montan ochenta y quatro maravedís (84)».

[mayo] «Yten que dió e pagó a Maestre Gonçalo ferrero de la obra por dos aparcobas (?) e dos paletas de fierro e otras ferramyentas que fizo para la obra de la pintura del Sagrario doscientos diez maravedís (210)».

[fol. $78 \mathrm{v}^{\circ}$ ] «Yten que dió e pagó en xiii de mayo a Maestre Gonçalo ferrero de la obra por una paleta e cinco fierros de azero que fiço para broñir el betuine de la pintura del Sagrario a diversos presçios en que montó doscientos e diez maravedís (210) e dieronse a Maestre Antonio pintor».

[fol. 88 y $88 \mathrm{v}^{\circ}$ ] En junio de 1483, se dan a Maestre Antonio 1.400 de cal para el betún.

Como podemos constatar, en la primavera y verano de 1483 se adquirían materiales para la pintura de la más importante obra figurativa que se estaba emprendiendo en la catedral toledana por estos años, la decoración del Sagrario, más tarde conocido como Sagrario Viejo. Como señalara en 1549 el canónigo Blas Ortiz en su Descripción ${ }^{55}$, este ámbito, de comparti-

\footnotetext{
${ }^{54}$ Véase J. A. Ceán Bermúdez, 1800, I, p. xv, n. 9, y F. Pérez Sedano, 1914, p. iii.

${ }^{55}$ Ramón Gonzálvez Ruiz y Felipe Pereda, La catedral de Toledo 1549. Según el Doctor Blas Ortiz Descripción gráphica y elegantísima de la S. I. de Toledo, Antonio Pareja Editor, Toledo, 1999, pp. 194-208.
} 
mentación laberíntica, se encontraba entonces, tras la capilla de Santa Marina, decorado con pinturas tanto en su interior como en su exterior; se trataba del espacio más sagrado del templo y el lugar donde se custodiaban no solo el tesoro sino las colección de reliquias. A pesar de haber desaparecido a finales del siglo xvI, para dar paso al Sagrario Nuevo, fue considerada, junto con el claustro y la biblioteca ${ }^{56}$, como la empresa pictórica más notable de las emprendidas por el Cardenal don Pedro González de Mendoza. Según Ortiz, constaba de un espacioso atrio, con función de relicario, que estaba adornado «primorosamente de muchas imágenes de santos, especialmente de San Eugenio, San Ildefonso y Santa Leocadia; el cual estriba en unas bóvedas doradas y el techo cerúleo y resplandeciente por todas partes de estrellas de oro».

La descripción del Quinientos encaja con los documentos de 1483 en los que se pone tanto énfasis en la compra de color azul destinado, entre otras cosas, para los abovedamientos ultramarinos y estrellados, pero que también resultó color protagonista de su pavimentación cuyos azulejos fueron traídos en 1496 desde Valencia ${ }^{57}$. Si en ese año de 1483 se iniciaban las labores de pintura, brilla por su ausencia de la documentación que se consultó en el siglo xvIII y todavía puede consultarse, Pedro Berruguete. Aunque se haya perdido, es necesario en cambio dar crédito a la noticia que daba como existente el contrato de Berruguete de 1488 para concluir la obra del Sagrario, dado que a él se remiten diferentes pagos posteriores. Así por ejemplo, los documentos inéditos que hoy aportamos, procedentes de las Actas Capitulares, del 11 de diciembre de 1490 y del 17 de octubre de 1497. En el primero, de la citada fecha de 1490 , se mandaba librar la importante cantidad de 40.000 maravedís, por la obra ya realizada ${ }^{58}$ : «Mandaron los señores deán y cabildo capitularmente ayuntados dar al señor maestrescuela [el doctor Francisco Álvarez] los maravedís que tenía reçebidos de los aliseres de la obra de los frutos deste año de xc el señor nunçio que ha de ser obrero el año que vyene de xci e el dicho señor nunçio quede de dar los 40.000 a Pedro Berruguete pyntor por lo que ha pyntado en el sagrario desta santa yglesia los quales 40.000 aseguró el capellán mayor don Alonso de Albornoz de los tornar en contante por este mes de diziembre».

Este primer documento se refiere a la decoración interior del Sagrario; dado que sabemos que también se extendía su ornato a la fachada del mismo, podríamos pensar en una nueva campaña, más tardía a la que correspondería el segundo pago, no menos importante y jamás transcrito, del 13 de enero de $1497^{59}$ : «Los señores maestrescuela e Alvar Pérez obrero ficieron relación a los dichos señores que tenían concordado e ygualado con Pedro Berruguete pyntor de darle 36.000 maravedís de la obra por la pyntura que hecho en el Sagrario de fuera desta santa yglesia que sy mandaban que se los diesen e los dichos señores ovieron por buena la dicha yguala y mandaron que se los pagaren los dichos 36.000 maravedís».

Según todos los documentos conocidos hasta la fecha ${ }^{60}$, si en 1488 Berruguete había con-

\footnotetext{
${ }^{56}$ Las pinturas de la biblioteca del claustro catedralicio, realizadas ya en tiempos del Cardenal Cisneros, fueron atribuidas en el siglo XviI, antes de su inmediata desaparición, al propio Berruguete; véase Felipe Fernández Vallejo, «Memorias i disertaciones, que podrán servir al que escriba la historia de la iglesia de Toledo», Real Academia de la Historia, Madrid, Ms. 24, p. 539.

${ }^{57}$ ACTOF 792 (1496), fol. 88.

${ }^{58}$ ACTAC 2 (1490-1501), fol. $11 \mathrm{v}^{\mathrm{o}}$

${ }^{59}$ ACTAC 2 (1490-1501), fol. 120. J. A. Ceán Bermúdez, I, p. 146 se refirió a una cantidad de 36.000, mientras que F. Pérez Sedano, p. 11 dió otra de 37.000.

${ }^{60}$ ACTOF 790, fol. 62, 1493: «Abiniose con Maestre Berruguete pyntor la obra de pintura que fiço dentro del sagrario santo desta santa yglesia por 75.000 maravedís e destos se le pagaron 72.050 maravedís e después fiço otra obra debaxo en los caxones e otras cosas para lo qual le mandó dar el cabildo otros 60.000 maravedís así que son todos 132.050 maravedís».

«Primeramente que recibió de Marcos Díaz quinze myll maravedís

Yten que recibió del señor capellán mayor en dos vezes treynta myll maravedís segund paresce por su quenta.

Yten que recibió el dicho Maestre Berruguete pyntor del señor protonotario Francisco Ortiz canónigo e obrero del año de 89 , para en quenta de la dicha pintura once myll y quatrocientos e quarenta maravedís.
}

AEA, LXXV, 2002, 300, pp. 361 a 380 
tratado la obra del Sagrario interior, recibiendo diversas partidas en 1489 y 1490 , por 75.000 maravedís, en 1493 había cobrado 72.050 y otros 60.000 que se le habían añadido en un nuevo concierto para «otra obra debaxo en los caxones e otras cosas», alcanzándose un total de 132.050 maravedís ${ }^{61}$. En 1497 recibió el finiquito de los 36.000 maravedís por los que se había obligado a la pintura del exterior del Sagrario. Por último, en 1501 pintó y cobró el conocido tablón de Nuestra Señora de la Esperanza.

En consecuencia, nadie parece haber visto un solo documento en que Pedro Berruguete hiciera acto de presencia en Toledo en 1483, sino sólo en 1488, incluso a beneficio de inventario. No obstante, los documentos citados están lejos de haber agotado su información. La transcripción de los mismos permite obtener otros datos más allá de los puramente económicos, de procederse a una correcta contextualización histórica. Aunque este aspecto de la investigación queda pendiente para un futuro desarrollo, no podemos dejar de pasar por alto la presencia en estos documentos de un hombre como el nuncio don Francisco Ortiz (ca. 1430-1508), figura que quizá pueda ayudar al dar luz al umbroso tema de las relaciones del pintor con el mundo italiano. Este converso, bien conocido como fundador del manicomio llamado «Hospital del Nuncio» de Toledo y responsable de muchas de las obras de la catedral de los años ochenta y noventa, presenta una movida biografía a caballo entre Roma y Toledo, que lo convierte en candidato para la aparición en la ciudad de un gusto «a la romana», al que Berruguete podría haber dado respuesta ${ }^{62}$. El silencio en el que ha caído este personaje, como estas obras toledanas desaparecidas, demuestran los problemas y las posibilidades todavía abiertas de la investigación sobre el palentino, que en su ensimismamiento ha dejado de tener en cuenta la necesidad de reconstruir el entorno vital para hacer elocuentes unos documentos aparentemente lacónicos y encontrar vias nuevas que canalicen tal labor.

Para terminar, otro tipo de problemas, en este caso de orden metodológico, requiere también nuestra reflexión. La renovación de los estudios de las relaciones artísticas entre el norte y el sur de Europa, entre el Atlántico y el Mediterráneo al que estamos asistiendo en los últimos años ${ }^{63}$, exige el replanteamiento del papel de la pintura castellana y aragonesa en este marco, y la necesidad de dotarnos de unos intrumentos de análisis formal e histórico más adecuados para individualizar los hipotéticos rasgos de una cultura visual hispana entre los dos modelos dominantes del panorama europeo. Solo asumiendo estos retos será posible superar una visión meramente catalográfica y una calificación taxonómica en el estudio del arte de Petrus Hispanus, Piero Spagnolo y Pedro Berruguete.

\footnotetext{
Yten que recibió del dicho señor capellán mayor en dos vezes catorce myll e seyscientos e cincuenta maravedís.

Yten que recibió del dicho señor capellán mayor don Alonso de Albornoz otros sesenta myll maravedís segund paresce firmado del nombre del dicho pintor Pedro Berruguete e de mano de Juan Palomo escrivano de la obra escripto». Recogido por R. M. Zarco del Valle, I, p. 21.

ACTOF 796, fol. 81, 1501: «En ix (9) días de febrero [de 1501], pagó el dicho señor obrero a Berruguete pintor tres myll maravedís por una ystoria de la esperança que pintó en un tablón para el Sagrario la qual dicha ystoria fue tasada por los señores obrero y visytadores estando juntamente en el Sagrario por los dichos tres myll maravedís de los quales se dió el dicho Berruguete por contento ante mi Alonso Contreras [notario apostólico]». Transcrito por F. Pérez Sedano, pp. 25-26.

${ }^{61}$ Estos «caxones» son las alhacenas citadas por Blas Ortiz, 1549, p. 202-203, donde se guardaban los ornamentos litúrgicos (cálices, mitras y los tres tomos de la Biblia de San Luis).

${ }^{62}$ Estuvo en Roma al menos dos veces, durante los pontificados de Pío II y Paulo II, de donde había vuelto ya en 1472 , y regresó de nuevo a Roma en julio de 1473 (véase ACTAC 1 (1466-1490), fol. 56), donde fue nombrado nuncio y protonotario apostólico por Sixto IV; véase F. de B. San Román, «Autobiografía de Francisco Ortíz», Boletín de la Real Academia de Bellas Artes y Ciencias Históricas de Toledo, 13, 1931, pp. 71-102; Ángel Fernández Collado, La catedral de Toledo en el siglo XVI. Vida, arte y personas, Diputación, Toledo, 1999, pp. 90-91.

${ }^{63}$ Renaissance Venice and the North: Crosscurrents in the Time of Bellini, Dürer and Titian, Londres-Milán, 1999; El Renacimiento mediterráneo: viajes de artistas e itinerarios de obras entre Italia, Francia y España en el siglo XV, ed. Mauro Natale, Museo Thyssen-Bornemisza, Madrid, 2001; La clave flamenca en los primitivos valencianos, ed. Fernando Benito Doménech y José Gómez Frechina, Museo de Bellas Artes de Valencia, Valencia, 2001; The Age of Van Eyck, 14301530. The Mediterranean World and early Netherlandish Painting, ed. Till-Holger Borchert, Ludion, Brujas, 2002.
} 


\begin{abstract}
APÉNDICE
[Archivio di Stato di Pesaro(Urbino), Antonio di Simone di Antonio Vanni, 44, fo 201.]

In nomine domini amen anno eiusdem nativitatis millesimo cccclxxvii ${ }^{\circ}$ indictionem decima tempore domini sixti divina prudentia pape quarti di Xv mensis aprilis in civitatis urbini et in domo quadam Illustrisimo principis nostri domini federici ducis urbini sita supra eius aulam iuxta et prope tam iuxta viam publicam et alia bona prefati Illustrismi ducis et alia latis praesentibus ser matheus [Matteo di ser Prosperi di Urbino] ser prosperi de urbini

et jacobo magistri petri [Jacopo di Mastropietro] maestro muratore de partibus lombardia habitatore urbini et testibus ad hec vocatus habitus et rogatus.

[al margen: «bartolomei brandani di urbino pax»]

Magister perus [espacio en blanco] spagnuolus pictor habitator Urbini per se et suos heredes omni meliori modo via iure et forma quibus magis melius et validius de ...? potuit et possit [ $\measuredangle$ ? ] fecit michi Antonio notario infrascripto tanquam predicte persone presenti et stanti et recipienti vice et nomine bartolomei brandani de brandanis de urbino generaliter de omni injuria malleficio et offensa per dictum bartolomeum facta et inflata contra dictum magistrum perum et specialiter de unam percusione [sic] ut dicitur facta et data [nota al margen: «per dictum bartolomeum»] cum quodam bastone sive ferro in capite dicti magistri peri, cuius occasione ut dicitur denunptiatus fuit seu contra eum fuisse processum in curia maleficiorum potestatis civitatis urbini ut dicitur patere in eius libris et ... quam pacem concordam et remissionem dictus magister petrus offensus promissit michi notario infrascripto ut supra stipulanti et recipienti semper et proprio firmam et ratam habere ... et contra ipsam non facta nec venire aliqua ratione vel causa de iure vel de facto sub pena viginti quinque librarum solepni stipulatione promissa qua soluta vel non predicta omnia omni tempore rata sint et firma pro quibus omnibus observandis obligavit omnia sua bona presentia et futura et rogans michi notario.

Ego Antonius ser Simonis de Urbino et quadra posterula publicus imperiale auctoritatis notarius praedictis omnibus et singulis praesens fui et ea rogatus subscripsi et publicavi signum meum conscretum apposui.

Die ... ultima et dicti mensis ante... dicto bartolomeo restitui.
\end{abstract}

